\title{
The promising role of epigenetic mediators and microRNAs in the early diagnosis of cholangiocarcinoma (Review)
}

\author{
VIKRANT RAI ${ }^{1,2}$, CHANDRA S. BOOSANI ${ }^{2}$ and DEVENDRA K. AGRAWAL ${ }^{2}$ \\ Departments of ${ }^{1}$ Biomedical Sciences, and ${ }^{2}$ Clinical and Translational Science, \\ Creighton University School of Medicine, Omaha, NE 68178, USA
}

Received May 15, 2019; Accepted August 7, 2019

DOI: $10.3892 /$ wasj.2019.18

\begin{abstract}
Cholangiocarcinoma (CC) is a highly lethal malignant tumor which arises from the biliary tract epithelium and is notoriously difficult to diagnose. Common risk factors for $\mathrm{CC}$ are primary sclerosing cholangitis, liver fluke infestation and hepatolithiasis. Although CCs are relatively uncommon tumors, the worldwide rising incidences and mortality rate for intrahepatic CC (ICC) renders it a disease of interest for research. CCs are usually fatal due to the typically late clinical presentation and the lack of effective non-surgical therapeutic modalities. The overall survival rate, including following tumor resection, is poor with $<5 \%$ of patients surviving 5 years and this rate has not significantly improved over the past 30 years. Thus, there is a need to diagnose $\mathrm{CC}$ at an early stage, and advances in immunohistochemistry, molecular genetics, pharmacogenomics and personalized medicine may aid in the study of the pathological basis of $\mathrm{CC}$ at the gene and protein level. Understanding the genetic and proteomic alterations in $\mathrm{CC}$ would not only increase the therapeutic efficacy, but would also provide a better treatment strategy. Epigenetic alterations that induce gene expression in cancers have been well established. Among the epigenetic mechanisms, targeting DNA hypermethylation and
\end{abstract}

Correspondence to: Dr Chandra S. Boosani, Department of Clinical and Translational Science, Creighton University School of Medicine, Criss II, Room 321, 2500 California Plaza, Omaha, NE 68178, USA

E-mail: ChandraBoosani@creighton.edu

Abbreviations: CC, cholangiocarcinoma; CDKN2A, cyclindependent kinase inhibitor 2A; DNMTs, DNA methyltransferases; ECC, extrahepatic cholangiocarcinoma; FHIT, fragile histidine triad; HATs, histone acetyltransferases; HDACs, histone deacetylases; HMTs, histone methyltransferases; ICC, intrahepatic cholangiocarcinoma; lncRNA, long non-coding RNA; MGMT, $O^{6}$-methylguanine-DNA methyltransferase; MINT, methylated in tumor gene; MRCP, magnetic resonance cholangopancreatography; NSCC, nodular-sclerosing cholangiocarcinoma; $\mathrm{p} 14^{\mathrm{ARF}}$, p14 alternate reading frame gene

Key words: cholangiocarcinoma, epigenetics, proteomics, DNA methylation, histone modification, immunohistochemistry, diagnostics, theranostics histone deacetylation with DNA methyltransferase (DNMT) and histone deacetylase (HDAC) inhibitors has been reported in a number of cancer types. In $\mathrm{CC}$, targeting the epigenetic pathways appears to be a promising approach for treatment. This review aims to provide a comprehensive overview of the putative role of epigenetic alterations and proteomic alterations in CC. Furthermore, the role of these alterations in early diagnosis, as prognostic markers, and therapeutics for better treatment strategies will be highlighted.

\section{Contents}

1. Introduction

2. Diagnostic snags

3. Mechanism of tumorigenesis

4. Epigenetic alterations in cholangiocarcinoma

5. Diagnostic development

6. Epigenetic therapy of cancer

7. Conclusions

\section{Introduction}

Cholangiocarcinoma (CC), arising from the biliary tract, is a rare malignant tumor accounting for almost $3 \%$ of all gastrointestinal cancers (1). On the basis of their location, two types of CCs have been characterized, namely intrahepatic CC (ICC) or extrahepatic CC (ECC) with clinical, pathological, epidemiological and molecular differences between them (2). The third one, which is considered as a sub-type of intrahepatic $\mathrm{CC}$ has also been described. These hilar cancers (Klatskin tumors) represents the most frequent category comprising 55-60\% of CCs. Non-hilar ECC comprises 20-30\% and ICC $10 \%$ of the total CC cases. More than $90 \%$ of CCs are adenocarcinomas (3). The common risk factors for CCs are primary sclerosing cholangitis (PSC), liver fluke infestation, congenital abnormalities, chronic hepatitis B virus infection, chronic hepatitis $C$ virus infection, and hepatolithiasis (4). Due to the typically clinically late diagnosis and unresectable disease at presentation and the lack of effective non-surgical therapeutic modalities, CCs are usually fatal and patients usually succumb to the disease within 12 months. Cancer cachexia, liver failure, recurrent sepsis secondary to biliary obstruction 
and the subsequent rapid decline in performance status mainly contribute to the high mortality rate associated with this type of cancer. The overall survival rate, including in patients who have undergone tumor resection, is poor, with $<5 \%$ of patients surviving 5 years. The poor survival rate has not improved significantly over the past 30 years (5). Although CC is a relatively rare tumor, the rising interest in this disease is due to the increasing incidence and mortality rates for ICC worldwide and the cause behind these remains unclear (4-9). Early lymph node metastasis and perineural invasion account for the poor outcome of patients with CC (10). Surgical liver resection with clear margins has been considered as the standard treatment for resectable CC; however, the survival rates are poor. Liver transplant has yielded some recent excellent results in highly selected patients with hilar CC; however, the major limitation is the shortage of cadaveric donor organs (11).

\section{Diagnostic snags}

Despite the development of the diagnostic and therapeutic modalities for various diseases and cancers, $\mathrm{CC}$ remains difficult to diagnose and continues to be a highly lethal disease with an extremely poor response to conventional anticancer therapies and a poor survival rate $(4,6)$. The poor prognosis and survival rate associated with $\mathrm{CC}$ is mainly due to the lack of early diagnosis. Although molecular markers, including CA 19-9, carcinoembryonic antigen (CEA), CA-125, platelet-derived growth factor and basic fibroblast growth factor are being used for diagnosis, these markers lack the sensitivity and specificity in early disease. Furthermore, CA19-9 has good sensitivity and specificity for $\mathrm{CC}$, but not for $\mathrm{CC}$ unassociated with primary sclerosing cholangitis (12). Thus, there is a need for the development of more effective and reliable markers for the early detection of CC. The study of genetic and epigenetic alterations mediating the molecular alterations and the malignant transformation of biliary cells occurring in CC may foster novel diagnostic, prognostic and therapeutic approaches (13). Developing interest in the molecular medicine and molecular genetics in the context of personalized, preventive, predictive and participatory medicine to provide better medical care in order to decrease the incidence and prevalence of the disease, as well as the study of the epigenetic alterations for the identification of genes involved in the tumorigenesis may prove to be beneficial (14). Since epigenetic alterations in gene expression are associated with $\mathrm{CC}$, genes that are differentially methylated in CC may be useful in providing valuable information on potential markers for the detection of early-stage curable disease, markers prognostic of response to specific treatments and overall prognosis and novel targets for the design of rational therapies $(4,6)$.

\section{Mechanism of tumorigenesis}

The accumulation of various defective cancerous or mutated genes results in the activation of multistep processes to induce tumorigenesis, resulting in $\mathrm{CC}$, which is characterized by the activation of growth-promoting genes and the silencing of tumor growth suppressor genes mediating the uncontrolled proliferation by altering the tissue homeostasis favorable for increasing the cell proliferation rate, decreasing cell death rate, and creating a growth-promoting environment (15). The main alterations in cancer gene functions in cell physiology are self-sufficiency in growth signals, insensitivity to growth-inhibitory signals, the evasion of apoptosis, limitless replicative potential, sustained angiogenesis and tissue invasion and metastasis (16). These changes may be due to genetic alterations in oncogenes or due to epigenetic alterations. Two major mechanisms, DNA methylation which adds methyl groups at $\mathrm{CpG}$ sites, to convert cytosine to 5-methylcytosine, and the post-translational histone modifications comprises the common epigenetic mechanisms in cancer $(4,6)$.

Epigenetics is an evolving area of research which can provide deeper insight, and improved diagnostics and theranostics for a number of human diseases. Epigenetic modifications include both heritable and non-heritable changes that regulate gene expression without altering the DNA sequence. Three major epigenetic mechanisms have been identified which are mediated through DNA methylation, histone modifications and non-coding RNAs. In DNA methylation, the cytosine residue at the CG sequence in DNA is specifically methylated, involving DNA methyltransferases (DNMTs), which results in the formation of 5-methycytosine. Subsequently, the methylated DNA fails to become transcribed and this results in gene silencing $(4,6)$. More than 11 different types of post-translational modifications on histone proteins have been described. Based on the type of modification on specific residues of histone proteins, gene expression becomes affected or induced, suggesting that histone modifications epigenetically regulate gene expression. Non-coding RNAs, which include microRNAs (miRNAs or miRs), siRNAs and long non-coding RNAs (lncRNAs) have also been identified to epigenetically affect gene expression. With the exception of IncRNAs, these RNA species bind to the complementary sequence on messenger RNA (mRNA) transcripts and thereby prevent protein translation. In a number of cancer types and in different human diseases, multiple different epigenetic mechanisms have been identified as key regulators which can induce and enhance the progression of disease. Therefore, targeting epigenetic mediators is considered to be very promising in drug development for the treatment of various human diseases $(4,5,13,17,18)$.

\section{Epigenetic alterations in cholangiocarcinoma}

DNA methylation. Studies have suggested that a number of genetic and epigenetic alterations occur during the neoplastic transformation of biliary epithelial cells that lead to the malignant progression of CC $(13,19,20)$. DNA methylation is the most well-studied epigenetic mechanism in CC. In CC tumorigenesis, the promoter regions of tumor suppressor genes are heavily methylated (promoter hypermethylation), leading to gene silencing. Genomic DNA is less methylated (global hypomethylation), resulting in increased genomic instability and the reactivation of transposon elements $(4,21,22)$. In CC, the promoter hypermethylation of genes involved in the cell cycle, cell adhesion, DNA repair, apoptosis and carcinogen/drug metabolism have been reported $(4,6)$. The most common cancer-related genes studied thus far in relation to $\mathrm{CC}$ are $\mathrm{K}$-ras, p53, p14 alternate reading frame gene (p14 $\left.{ }^{\mathrm{ARF}}\right), \mathrm{p} 16^{\mathrm{INK} 4 \mathrm{a}}$, SFRP1, SFRP2 and $\beta$-catenin $(4,6,22)$ (Table I). The majority of K-ras gene mutations occur in codon 12. Genetic alterations, 
such as point mutations of K-ras and p53 have been frequently found in a subset of CC cases (24-27); however, the mutation or deletion of the cell cycle regulators, $\mathrm{p} 14^{\mathrm{ARF}}$ and $\mathrm{p} 16^{\mathrm{INK} 4 \mathrm{a}}$, are not frequent $(28,29)$. Although $\beta$-catenin overexpression is frequently encountered in $\mathrm{CC}$, mutations in the $\beta$-catenin gene have not been identified in ICC to date, at least to the best of our knowledge (30). These results suggest the crucial role of DNA methylation in the tumorigenesis of $\mathrm{CC}$ and the potential of studying these epigenetic alterations in order to identify and develop improved and more effective therapeutic modalities in the future (22) (Table I).

Methylated $\mathrm{CpG}$ islands in tumor genes termed methylated in tumor gene (MINT) are associated with carcinogenesis of the biliary tract epithelium and other epithelial cancers. The MINT loci associated with CC may be $\mathrm{CpG}$ island methylator phenotype (CIMP)-positive or -negative, depending on the histological type of CC (20). The methylation of various genes presented in Table $I$ is associated with a poor survival and increased tumorigenesis; however, the methylation of DcR1, the decoy receptor, is associated with a significantly longer overall survival. This suggests that the identification of specific epigenetic alterations may serve as a prognostic marker in $\mathrm{CC}$. Furthermore, the positivity of epigenetic alterations in the less differentiated $\mathrm{CC}$, but not in normal adjacent tissue, suggests the potential role of epigenetic biomarkers for prognosis and diagnosis (46). Furthermore, intraepithelial biliary neoplasms (IEBNs), the mucosal extension of carcinoma and preinvasive neoplastic lesions in the bile ducts around $\mathrm{CC}$ have been found to be associated with nodular-sclerosing CC (NSCC), a common $\mathrm{CC}$ of the intrahepatic large, perihilar and distal bile ducts. Immunohistochemical analysis with S100P, vimentin, S100A4, E-cadherin, MUC1, MUC2, MUC5AC, MUC6, CDX2, CK7, CK20, CDX2, CD10, p53 and Ki67 in NSCC has revealed a pre-invasive and cancerous lesion zone (49). Since, epigenetic alterations are found in less differentiated $\mathrm{CC}$, but not in normal adjacent tissue, studying the epigenetic and proteomic alterations in pre-invasive compared to cancerous lesions, may prove to be beneficial for the development of more effective treatment strategies.

Histone modifications. Histones, complex with genomic DNA to form nucleosomes, which consist of two turns of DNA wrapped around a histone octamer composed of two subunits of each histone, $\mathrm{H} 2 \mathrm{~A}, \mathrm{H} 2 \mathrm{~B}, \mathrm{H} 3$ and $\mathrm{H} 4$, with $\mathrm{H} 1$ as the linker histone between the core nucleosomes (50). Post-transcriptional modifications and gene expression through histones are often regulated by histone acetylation, methylation and phosphorylation (13). Covalent modifications, such as the acetylation of lysines, the methylation of lysines and arginines, the phosphorylation of serines and threonines, and the ubiquitination of lysines occur at the N-terminal tails of histone proteins, protruding out from the core nucleosomes (51). Histone can be mono-, di- or tri-methylated and $\mathrm{H} 3$ (lysines 4, 9 and 27) and $\mathrm{H} 4$ (lysine 20) are the most frequently methylated histones (52-53). Histone acetylation and deacetylation catalyzed by histone acetyltransferases (HATs) and histone deacetylases (HDACs) results in transcriptional activation and repression, respectively (54). However, depending on the type of amino acid and its position in the histone tail, histone methylation catalyzed by histone methyltransferases (HMTs) may result in either transcriptional activation or repression (55). Similarly, H3K9, $\mathrm{H} 3 \mathrm{~K} 27$ and H4K20 methylation results in transcriptional repression, while $\mathrm{H} 3 \mathrm{~K} 4$ methylation results in transcriptional activation (56). The overexpression of HDAC1 is associated with malignant behaviour and a poor prognosis of ICC (57). Reduced survival and cell growth arrest in the human $\mathrm{CC}$ cell lines with HDAC inhibitors, such as MS-275, trichostatin A, NVPLAQ824 and NVPLBH589 in a dose-dependent manner, suggests the possibility of suppressing CC with HDAC inhibitors (58-60). Furthermore, the synergistic growth inhibitory effect by the induction of apoptosis and cell cycle arrest by HDAC inhibitors with conventional cytostatic drugs, such as gemcitabine, doxorubicin, sorafenib, or bortezomib supports the therapeutic role of HDAC inhibitors in treating CC $(58,60)$. However, the role of histone modifications in the carcinogenesis and pathogenesis of CC is not well documented; thus, further research to explore and unravel this conundrum is required in order to develop more effective diagnostic and therapeutic strategies for the treatment of CC.

miRNAs. miRNAs are small non-coding RNAs derived from polyadenylated primary miRNAs (pri-miRNAs) and precursor miRNAs (pre-miRNAs) involving RNA polymerase II and RNase III Drosha and pasha/DGCR8 (61). The maturation of miRNAs is mediated by RNase III Dicer and binding with RISC (RNA-induced silencing complex). Mature miRNAs regulate gene expression at the post-transcriptional level by binding to the $3^{\prime}$ untranslated region (3'UTR) of target mRNAs, which leads to degradation of mRNAs (62). The upregulation (overexpression) or downregulation (underexpression) of miRNAs regulates gene expression, thereby regulating tumorigenesis (Table II). The role of several miRNAs as oncogenes and tumor suppressor genes (63) and as diagnostic and prognostic markers (17) has been documented. Recently, the presence of the increased expression of oncogenic miR-24 and the decreased expression of the tumor suppression gene, multiple endocrine neoplasia type 1 (also known as menin 1 (MEN1)), and the role of miR-24 inhibition in attenuating the progression of $\mathrm{CC}$ has been discussed (64). Since MEN1 overexpression is associated with the decreased proliferation, angiogenesis, migration and invasion of $\mathrm{CC}$, the inhibition of miR-24 resulting in an increased MEN1 protein expression may attenuate the proliferation, angiogenesis, migration and invasion of CC. Thus, targeting miR-24 may prove to be a novel therapeutic strategy.

DNA methylation, histone modification and alterations in miRNA expression are involved in the tumorigenesis of CC. Furthermore, the control of the transcription of miRNAs by DNA methylation, histone modifications and the regulation of epigenetic machinery by miRNAs suggest an association of these mechanisms in CC tumorigenesis. This suggests that the study of epigenetic alterations may provide novel and non-invasive biomarkers, strong potential screening tools, and potentially promising prognostic and diagnostic markers for $\mathrm{CC}$ in clinical practice $(18,72-74)$.

IncRNAs. IncRNAs pervasively transcribed in the genome, are emerging as crucial regulators of cancer and play important roles in almost every aspect of cell biology, including tumorigenesis. IncRNAs regulate the malignant transformation 


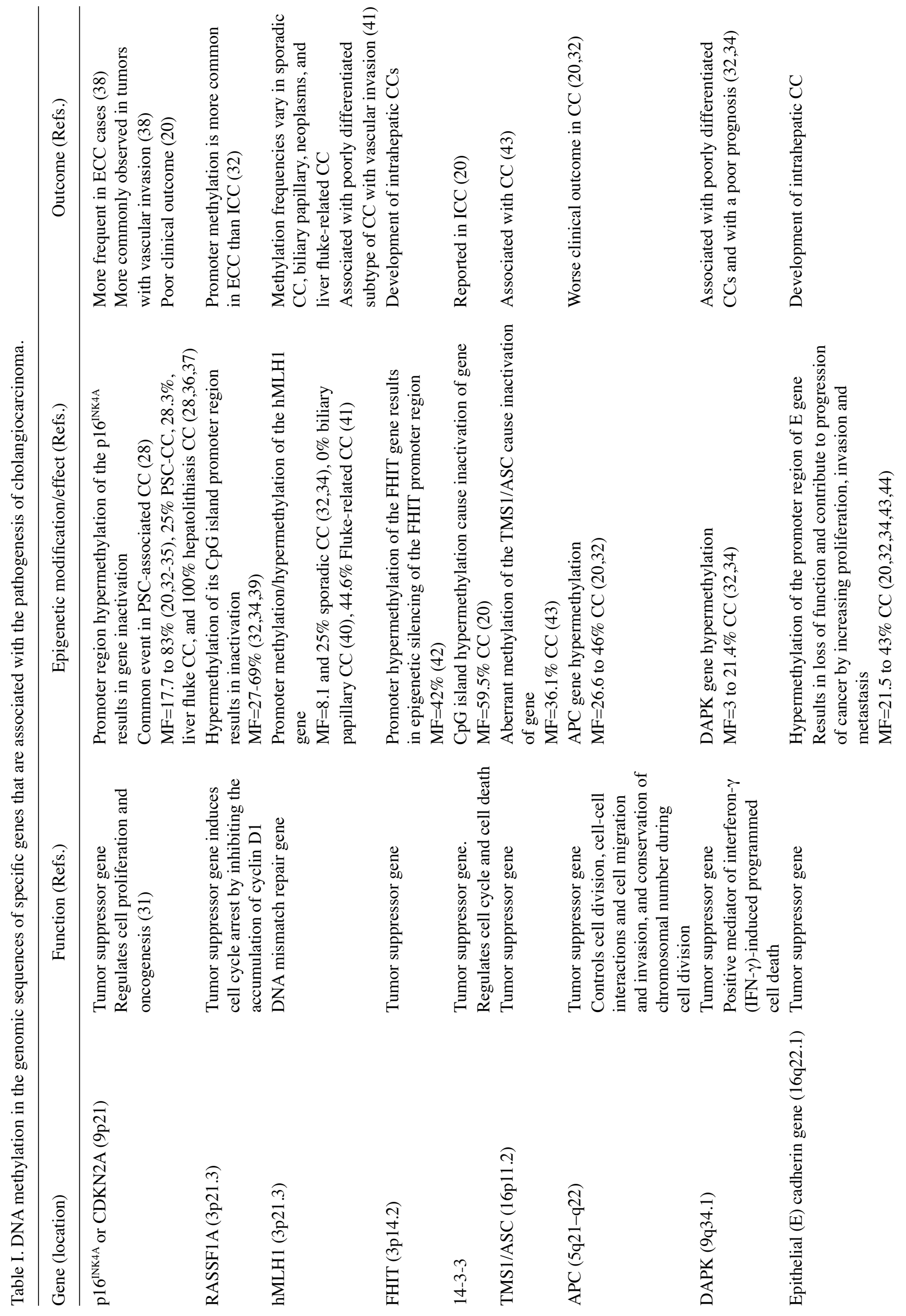




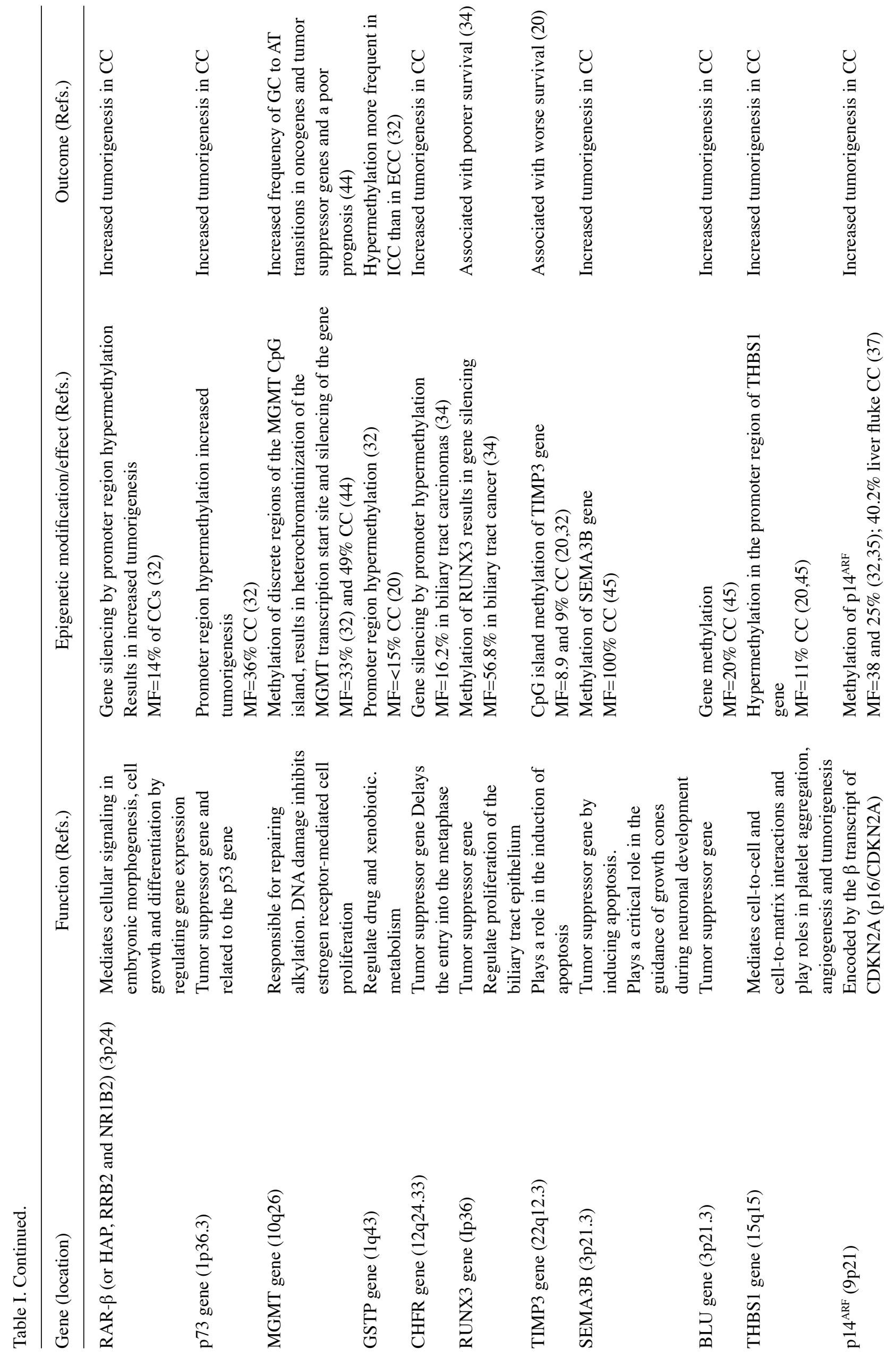


of cells through their interaction with DNA, proteins and RNA. Thus, lncRNA molecular mechanisms involved in the tumorigenesis of $\mathrm{CC}$ may be attractive targets for therapeutic intervention in the fight against cancer (75-77). Using lncRNAs, mRNA microarrays and RT-PCR, Wang et al (78) examined the associations between the expression levels of lncRNAs and target genes, and found the upregulation of lncRNAs in ICC tissues and the downregulation of lncRNAs in non-cancerous tissues. The majority of upregulated genes are involved in carcinogenesis, hepatic system diseases and signal transductions. Furthermore, the upregulation of lncRNA CCAT1 and lncRNA AFAP1-AS1 in CC and their association with the tumor growth promotion, aggressive malignant behavior and the metastasis of $\mathrm{CC}$ suggest the role of lncRNAs in the pathogenesis of CC (79-80). Competing endogenous RNAs (ceRNAs) are a novel class of RNA species that can regulate miRNAs, IncRNAs, and genes that play important roles in the pathogenesis of CC (81). The interaction between IncRNA MALAT1 and miR-204 has been shown to modulate human hilar CC proliferation, migration and invasion by targeting CXCR4 (82). Wang et al (76) found that cell migration and invasion in CC, by targeting IL-6 and CXCR4 via ceRNA, was regulated by lncRNA H19 and HULC, upregulated by oxidative stress. Furthermore, the co-expression of the carbamoyl-phosphate synthase 1 (CPS1) gene and its IncRNA has been shown to be associated with a poor prognosis in CC (83). Hence, the increased expression of lncRNAs in CC indicates that IncRNAs may be potential diagnostic and prognostic biomarkers for ICC; the combined assessment of lncRNA and mRNA expression levels may thus predict the survival of patients with ICC $(76-80,83)$. Furthermore, the BRCA-1 associated protein-1 (BAP1)-dependent expression of IncRNA NEAT- 1 enhancing the sensitivity to gemcitabine in $\mathrm{CC}$, suggests the therapeutic role of IncRNAs (84).

Protein modifications. Post-transcriptional modifications result in the alteration of protein functions following protein expression and are associated with carcinogenesis and a number of human diseases. The wingless type (Wnt) signaling pathway plays a crucial role in the tumorigenesis of CC. Davaadorj et al $(85,86)$ found a negative correlation between secreted frizzled-related protein-1 (SFRP1) expression and $\beta$-catenin expression in ICC and suggested that the loss of the negative regulator of the Wnt signaling pathway, SFRP1, located at chromosome 8p12e11.1, was associated with a poor prognosis of patients with ICC. Hence, the loss of SFRP1 may be a potential prognostic biomarker for ICC. These data suggest that proteomics analysis may be useful for the diagnosis and prognosis in CC. Furthermore, the differential expression of proteins during proteomics analysis may be used for the identification of the transition of the infectious liver to $\mathrm{CC}$, and may thus lead to the early diagnosis and prevention of CC (87).

\section{Diagnostic development}

Immunohistochemistry. The immunostaining of formalin-fixed biopsied tissues with various tumor-specific markers, including CD10, CEA, CK7, CK20, CDX-2, TTF-1, ER, PR, BRST-2, ISH $^{\text {albumin }}$, Hep Par 1, Ber-Ep4, chromogranin and PSA is being used to differentiate and diagnose CC (88). However, due to the 
Table II. Unique microRNAs that were identified to promote the pathogenesis of cholangiocarcinoma.

\begin{tabular}{llll}
\hline Overexpressed or upregulated miRNAs & Target gene & \multicolumn{1}{c}{ Correlation with CC tumorigenesis } \\
\hline miR-141 & CLOCK & Tumor suppressor gene \\
miR-200b & PTPN12 & Tumor suppressor gene \\
miR-21 & PTEN & Tumor suppressor gene \\
let-7a & NF2 & Tumor suppressor gene \\
miR-24 & MEN1(11q13) & Tumor suppressor gene \\
miR-26a & GSK-3b & Tumor growth \\
miR-429 & CDH-6 & Tumor suppressor gene \\
miR-21, miR-31, and miR-223 & Multiple & No association with clinic-pathological parameters of CC & $(68)$ \\
\hline
\end{tabular}

Underexpressed or downregulated

miRNAs Target gene Correlation with CC tumorigenesis

(Refs.)

$\begin{array}{lll}\text { miR-29b } & \text { MCL-1 } & \text { Tumor suppressor gene } \\ \text { miR-370 } & \text { MAP3K8 } & \text { Tumor suppressor gene } \\ \text { miR-148a } & \text { DNMT-1 } & \text { Regulate methyltransferase } \\ \text { miR-152 } & \text { DNMT-1 } & \text { Regulate methyltransferase } \\ \text { miR-124 } & \text { SMYD3 } & \text { Migration and invasion of CC cells } \\ \text { miR-214 } & \text { Twist } & \text { Oncogene } \\ \text { miR-122, miR-145, miR-200c, miR-221, } & \text { Multiple } & \text { Associated with tumorigenesis of ICC }\end{array}$

and miR-222

close association of the anatomic sites in the embryonic and the fetal development process of ICC from metastatic pancreatic ductal adenocarcinomas or adenocarcinoma from the upper GI tract, it has become difficult to differentiate due to the lack of tissue-specific markers (88). The inclusion of non-conventional markers (placental S100 (S100P), von Hippel-Lindau tumor suppressor (pVHL), mucin 5AC (MUC5AC) and CK17) with the existing markers may be beneficial (89). Despite the presence of various diagnostic and prognostic markers (17), early diagnosis remains a challenge and indicates thea need for more effective histological and molecular diagnostics. Nakanuma et al (49) suggested the role of S100P immunostaining in the differentiation of carcinomatous, perihilar and normal tissue. Recently, Kanzawa et al (90) discussed the role of dual immunostaining for maspin and p53 compared to S100P and p53 on cell blocks in increasing the diagnostic value of biliary brushing cytology. The role of tubulin $\beta$-III (TUBB3) as a novel immunohistochemical marker for intrahepatic peripheral $\mathrm{CC}$ has also been discussed (91).

Proteomics. The serum markers, CA19-9, CA125 and CEA, have been used for the diagnosis of $\mathrm{CC}$; however, their sensitivity and specificity for all histological types of $\mathrm{CC}$ is unclear (12). Thus, there is a need for more effective markers for early diagnosis. Patel et al (12) suggested that the addition of serum CA19-9 may aid in the differentiation of CC in patients with PSC and CC not associated with PSC. Including the proteomic-based autoantibodies analysis against heat shock protein 70, enolase 1 and ribonuclease/angiogenin Inhibitor 1 as diagnostic markers may increase the sensitivity and specificity in the early detection of CC $(92,93)$. Similarly, using matrix-assisted laser desorption/ionization-imaging mass spectrometry (MALDI IMS) to reveal tissue heterogeneity in hepatic CC may aid in revealing novel relevant biomarkers for CC. Furthermore, these biomarkers may be used for diagnostic and follow-up purposes in patients who are at risk of developing $\mathrm{CC}$ if these are secreted and detectable in blood (94). Further, the mass spectrometry-based proteomics analysis of formali n-fixed-paraffin-embedded extrahepatic CC and the overexpression of proteins on immunohistochemical analysis with a positive rate of S100P (84\%), CEAM5 (75\%), MUC5A (62\%), OLFM4 (60\%), OAT (42\%), CAD17 (41\%), FABPL (38\%), AOFA (30\%), K1C20 (25\%) and CPSM (22\%) in extrahepatic $\mathrm{CCs}$, but not in normal tissue, suggest the potential role of proteomics analysis in elucidating potential targets for future diagnostic biomarkers and therapy (95). Stephenson et al (96) also highlighted the role of proteomics profiling for the quantitative assessment of cell surface proteins to identify novel therapeutic targets in $\mathrm{CC}$ and to distinguish between distal CC and pancreatic cancers. Additionally, proteomics profiling for the identification of novel serum biomarkers may aid in differentiating between $\mathrm{CC}$ from benign biliary tract diseases (97). The same reports also described FAM19A5, MAGED4B, KIAA0321, RBAK and UPF3B as potential biomarkers of CC. These data suggest that proteomics profiling may be used to elucidate the potentially novel biomarker for the development of diagnosis, prognosis and therapies (98-100).

Epigenetics. Tissue heterogeneity in carcinomas confers a significant problem in early diagnosis. Although single-gene predictive assays are available, there is a need for the analysis of multiple gene loci, since the genetic, proteomic and miRNA content may vary in the biopsied sample due to tissue heterogeneity $(14,49)$. Whole-genome sequencing and RNA sequencing 


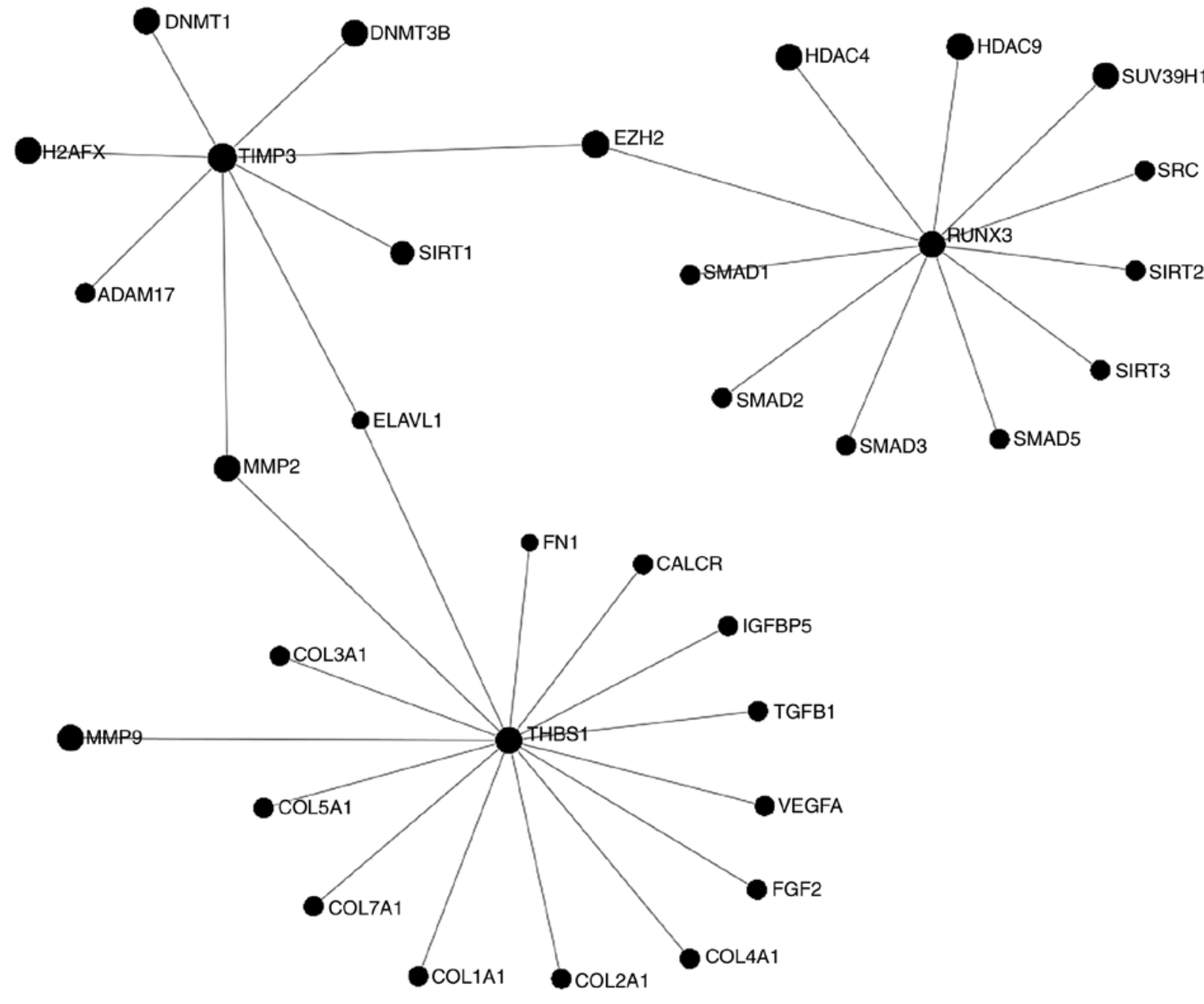

Figure 1. Epigenetic regulations in cholangiocarcinoma. Proteins that epigenetically regulate cholangiocarcinoma as identified through network analyst are shown. Key proteins that regulate epigenetic mechanisms are shown. Image shows proven/predicted interactions between different epigenetic regulators that were identified using the online software at www.networkanalyst.ca.

may provide a comprehensive analysis of the somatic mutations and gene expression, and provide novel insights on the use of genomic data for the treatment of individual patients (14). Furthermore, genome-wide expression patterns associated with oncogenesis and the sarcomatous transdifferentiation of $\mathrm{CC}$ documented the up- and downregulation of tumor-related and tumor suppressor genes and proteins in human $\mathrm{CC}$, including SPP1, EFNB2, E2F2, IRX3, PTTG1, PPAR $\gamma$, KRT17, UCHL1, IGFBP7 and SPARC (101). This suggests that gene expression profiling for the deregulation of oncogenes, tumor suppressor genes and methylation-related genes, and their related proteins may be useful for the identification of molecular targets for the diagnosis and prognosis of CC. Furthermore, gene expression profiling may also be useful in differentiating $\mathrm{CC}$ from other liver masses in addition to subclassifying ICC, with better results compared to histopathological findings. Furthermore, gene profiling can also be helpful in predicting the outcome for various therapeutic modalities and patient survival (101).

\section{Epigenetic therapy of cancer}

Epigenetic alterations result in the inactivation and silencing of tumor suppressor genes and increased tumorigenesis.
Signal transducer and activator of transcription 3 (STAT3) overexpression is associated with metastasis and poor post-surgical outcome in CC, and the inhibition of STAT3 may be a novel therapeutic target (102). Similarly, Braconi et al (103) discussed the potential of targeting the IL-6 dependent phenotype through a computational bioinformatics analysis of phenotype-based gene expression. The Wnt/catenin pathway plays a crucial role in CC tumorigenesis and the reversal of the silencing of genes involved in Wnt signaling, including SOX17, WNT3A, DKK2, SFRP1, SFRP2 and SFRP4 with DNMT inhibitor 5-aza-2'deoxycytidine in CC cells suggests the significance of targeting epigenetic mediators in CC (22). Although 5-azacitidine and 5-aza-2'deoxycytidine are US Food and Drug Administration (FDA)-approved drugs for the treatment of myelodysplastic syndrome, the in vitro and in vivo toxicity of these drugs show instability in neutral solutions $(104,105)$. The role of the less toxic DNMT inhibitor, zebularine, a novel DNA methyltransferase inhibitor, alone or in combination with other DNMT inhibitors to enhance the re-expression of epigenetically silenced genes in cancer cells and as an inducer of cell death in CC, has been discussed (106-108). Thus, the re-activation of the silenced gene may restore gene function 
and its tumor-suppressing actions; thus, from this perspective, demethylating agents and HDAC inhibitors may be useful as drug candidates (22,57-60). Cell growth arrest and cell death in cancer cells can be induced by HDAC inhibitors. Another advantage with HDAC inhibitors is that normal cells are relatively resistant to them. The HDAC inhibitor, suberoylanilide hydroxamic acid (SAHA), has been approved by the FDA for T-cell cutaneous lymphoma treatment. Furthermore, the role of SAHA, valproic acid and the EZH2 inhibitor, 3-deazaneplanocin-A, as therapeutic drugs in $\mathrm{CC}$, has also been discussed (109-112). Since molecular genetics, epigenetics and proteomics are evolving and promising fields in research, the study of the epigenetics of $\mathrm{CC}$ may enhance the effectiveness of $\mathrm{CC}$ therapeutics. Furthermore, targeting the specific phenotype and pathways involved in the carcinogenesis of $\mathrm{CC}$, and the use of the computational bioinformatics-driven approach to discover a novel drug may prove to be beneficial (103). The key proteins regulating the epigenetic mechanisms in the pathogenesis of $\mathrm{CC}$ are presented in Fig. 1.

Based on the above-mentioned study results, it is imperative that despite the advancements in diagnostic tools and treatment strategies, the early diagnosis and treatment of CC remains challenging. Since the most common identified cause of CC is PSC, the diagnosis of early-stage CC requires a high index of suspicion in patients with PSC. Furthermore, due to the negative results of endoscopic brush cytology, endoscopic biopsies and imaging studies, a regular follow-up with magnetic resonance cholangopancreatography (MRCP) and advanced imaging, such as positron emission tomography (PET) scan should be carried out in all patients with PSC. Along with the PET scan, a promising imaging modality for the diagnosis of CC, namely the determination of serum levels of CA19-9, CA125 and CEA, should be carried out in an annual follow-up. Although the sensitivity and specificity of these biomarkers for all histological types of CC is unclear, CA19-9 values $>100 \mathrm{U} / \mathrm{ml}$ have a $75 \%$ sensitivity and $80 \%$ specificity for CC (113). Since there are no clinical surveillance guidelines for the early detection of sporadic $\mathrm{CC}$, the screening of patients with PSC with MRI, MRCP PET scan, and the determination of CA19-9 levels, is the most effective strategy for early detection. Since DNA hypermethylation is the most common aberrant epigenetic alteration in CC, the early detection of the $\mathrm{CC}$ can also be facilitated by DNA methylation assay of the bile fluids, including a panel of CCND2, CDH13, GRIN2B, Runt-related transcription factor 3 (RUNX3) and Twist-related protein 1 (TWIST1). This method for the detection of CC has a sensitivity of $83 \%$ and a specificity of $100 \%(13,114,115)$. Screening for the genetic and epigenetic alterations in the precursor lesions, including intraductal papillary neoplasm of the bile duct (IPNB) and biliary intraepithelial neoplasia (BilIN), as discussed by Ettel et al, may also be beneficial (116). The diagnostic and treatment challenges are also due to the heterogeneity of clinical presentations, which may be due to the origin of CC from topographically heterogeneous cholangiocytes. In cases of ICC, clinical presentation is highly heterogenous (mass-forming type, infiltrative type, etc.) and genetic alterations in cases with mass-forming type (ICC) have been shown to be similar to those in cases with hepatocellular carcinoma, and in cases with infiltrative type, genetic alterations have been shown to be similar with those in cases with perihilar CC. The clinicopathological, immunohistochemical and molecular profile similarity of Muc-ICCs with hilar CCs (from mucin-producing cholangiocytes) and of mixed-ICCs with CLCs (thought to be of HPC origin) and varying degrees of biliary epithelial differentiation has been reported $(117,118)$. Due to the complexity of origin and clinical presentation, the treatment of CC as a whole is difficult, and there is a need to focus on the site of origin for treatment. In other words, individualized treatment should be preferred for the treatment of CC. In early-stage CC (perihilar CCA), liver transplantation with pre-operative radiation and chemotherapy and exploratory laparotomy needs to be performed to ensure the absence of metastases as a viable therapeutic option, whereas patients with ICC can be treated surgically $(113,119)$.

\section{Conclusions}

CCs are rare notoriously malignant tumors with a very poor survival rates even following surgical resection. The delayed presentation of the tumor is the main reason for the delayed diagnosis and poor survival. Currently, the available panel of tissue and serum biomarkers can diagnose the tumor at a late stage only, and is lacking any modalities for diagnosis at an early stage. Thus, there is a need for the identification of more effective diagnostic biomarkers for the early diagnosis of CC. Recent advances in immunohistochemistry and molecular genetics paved the way for improved diagnostics. The role of epigenetic and proteomic alterations in the pathogenesis of CC has been documented, and these alterations may serve as the early diagnostic and prognostic markers for CC. Furthermore, the role of epigenetic therapy with DNMT and HDAC inhibitors discussed in the literature are in the early stages of clinical trials. The findings of various studies discussed in this review suggest that epigenetic and proteomic alterations may serve as more effective diagnostic markers for CC in the early stages, and epigenetic therapy may be beneficial for the treatmetn of $\mathrm{CC}$. However, further research is required to investigate the initial events occurring in CC.

\section{Acknowledgements}

Not applicable.

\section{Funding}

This study was supported by Creighton University LB692 Clinical and Translational Research Grant to CSB.

\section{Availability of data and materials}

Not applicable.

\section{Authors' contributions}

VR, CSB and DKA were involved in the conception and design of the study. Drafting of the article was performed by VR. Critical revisions in the article were carried out by VR and CSB. All authors have read complete manuscript. 


\section{Ethics approval and consent to participate}

Not applicable.

\section{Patient consent for publication}

Not applicable.

\section{Competing interests}

The authors declare that they have no competing interests.

\section{References}

1. Vauthey JN and Blumgart LH: Recent advances in the management of cholangiocarcinomas. Semin Liver Dis 14: 109-114, 1994.

2. Lazaridis $\mathrm{KN}$ and Gores GJ: Cholangiocarcinoma Gastroenterology 128: 1655-1667, 2005.

3. Khan SA, Davidson BR, Goldin R, Pereira SP, Rosenberg WM, Taylor-Robinson SD, Thillainayagam AV, Thomas HC, Thursz MR and Wasan H; British Society of Gastroenterology: Guidelines for the diagnosis and treatment of cholangiocarcinoma: Consensus document. Gut 6 (Suppl 51): VI1-9, 2002.

4. Sandhu DS, Shire AM and Roberts LR: Epigenetic DNA hypermethylation in cholangiocarcinoma: Potential roles in pathogenesis, diagnosis and identification of treatment targets. Liver Int 28: 12-27, 2008.

5. Shaib Y and El-Serag HB: The epidemiology of cholangiocarcinoma. Semin Liver Dis 24: 115-125, 2004.

6. Limpaiboon T: Epigenetic aberrations in cholangiocarcinoma: Potential biomarkers and promising target for novel therapeutic strategies. Asian Pac J Cancer Prev 13 (Suppl): S41-S45, 2012.

7. Khan SA, Taylor-Robinson SD, Toledano MB, Beck A, Elliott P and Thomas HC: Changing international trends in mortality rates for liver, biliary and pancreatic tumours. J Hepatol 37: 806-813, 2002.

8. Patel T: Worldwide trends in mortality from biliary tract malignancies. BMC Cancer 2: 10, 2002.

9. Shaib YH, Davila JA, McGlynn K and El-Serag HB: Rising incidence of intrahepatic cholangiocarcinoma in the United States: A true increase? J Hepatol 40: 472-477, 2004.

10. Rosai J: Ackerman's Surgical Pathology. Vol 2. 8th edition. Mosby, pp982-989, 1996

11. Rea DJ, Heimbach JK, Rosen CB, Haddock MG, Alberts SR, Kremers WK, Gores GJ and Nagorney DM: Liver transplantation with neoadjuvant chemoradiation is more effective than resection for hilar cholangiocarcinoma. Ann Surg 242: 451-458, discussion 458-461, 2005

12. Patel AH, Harnois DM, Klee GG, LaRusso NF and Gores GJ: The utility of CA 19-9 in the diagnoses of cholangiocarcinoma in patients without primary sclerosing cholangitis. Am J Gastroenterol 95: 204-207, 2000.

13. Maroni L, Pierantonelli I, Banales JM, Benedetti A and Marzioni M: The significance of genetics for cholangiocarcinoma development. Ann Transl Med 1: 28, 2013.

14. Sheffield BS, Tessier-Cloutier B, Li-Chang H, Shen Y, Pleasance E, Kasaian K, Li Y, Jones SJ, Lim HJ, Renouf DJ, et al: Personalized oncogenomics in the management of gastrointestinal carcinomas-early experiences from a pilot study. Curr Oncol 23: e571-e575, 2016.

15. Ashkenazi R, Gentry SN and Jackson TL: Pathways to tumorigenesis-modeling mutation acquisition in stem cells and their progeny. Neoplasia 10: 1170-1182, 2008.

16. Hanahan D and Weinberg RA: The hallmarks of cancer. Cell 100 $57-70,2000$.

17. Berretta M, Cavaliere C, Alessandrini L, Stanzione B,Facchini G, Balestreri L, Perin T and Canzonieri V: Serum and tissue markers in hepatocellular carcinoma and cholangiocarcinoma: Clinical and prognostic implications. Oncotarget 8: 14192-14220, 2017.

18. Zhou J, Liu Z, Yang S and Li X: Identification of microRNAs as biomarkers for cholangiocarcinoma detection: A diagnostic meta-analysis. Clin Res Hepatol Gastroenterol 41: 156-162, 2017.

19. Rashid A: Cellular and molecular biology of biliary tract cancers. Surg Oncol Clin N Am 11: 995-1009, 2002.
20. Lee S, Kim WH, Jung HY, Yang MH and Kang GH: Aberrant $\mathrm{CpG}$ island methylation of multiple genes in intrahepatic cholangiocarcinoma. Am J Pathol 161: 1015-1022, 2002.

21. Herman JG and Baylin SB: Gene silencing in cancer in association with promoter hypermethylation. N Engl J Med 349: 2042-2054, 2003.

22. Goeppert B, Konermann C, Schmidt CR, Bogatyrova O, Geiselhart L, Ernst C, Gu L, Becker N, Zucknick M, Mehrabi A, et al: Global alterations of DNA methylation in cholangiocarcinoma target the Wnt signaling pathway. Hepatology 59: 544-554, 2014

23. Meng F, Henson R, Lang M, Wehbe H, Maheshwari S, Mendell JT, Jiang J, Schmittgen TD and Patel T: Involvement of human micro-RNA in growth and response to chemotherapy in human cholangiocarcinoma cell lines. Gastroenterology 130: 2113-2129, 2006.

24. Kang YK, Kim WH, Lee HW, Lee HK and Kim YI: Mutation of p53 and K-ras, and loss of heterozygosity of APC in intrahepatic cholangiocarcinoma. Lab Invest 79: 477-483, 1999.

25. Sturm PD, Baas IO, Clement MJ, Nakeeb A, Johan G, Offerhaus A, Hruban RH and Pitt HA: Alterations of the p53 tumor-suppressor gene and K-ras oncogene in perihilar cholangiocarcinomas from a high-incidence area. Int J Cancer 78: 695-698, 1998.

26. Kiba T, Tsuda H, Pairojkul C, Inoue S, Sugimura $T$ and Hirohashi S: Mutations of the p53 tumor suppressor gene and the ras gene family in intrahepatic cholangiocellular carcinomas in Japan and Thailand. Mol Carcinog 8: 312-318, 1993.

27. Wattanasirichaigoon S, Tasanakhajorn U and Jesadapatarakul S: The incidence of K-ras codon 12 mutations in cholangiocarcinoma detected by polymerase chain reaction technique. J Med Assoc Thai 81: 316-323, 1998.

28. Ahrendt SA, Eisenberger CF, Yip L, Rashid A, Chow JT, Pitt HA and Sidransky D: Chromosome 9p21 loss and p16 inactivation in primary sclerosing cholangitis-associated cholangiocarcinoma. J Surg Res 84: 88-93, 1999.

29. Tannapfel A, Benicke M, Katalinic A, Uhlmann D, Köckerling F, Hauss J and Wittekind C: Frequency of p16(INK4A) alterations and K-ras mutations in intrahepatic cholangiocarcinoma of the liver. Gut 47: 721-727, 2000.

30. Sugimachi K, Taguchi K, Aishima S, Tanaka S, Shimada M, Kajiyama K, Sugimachi K and Tsuneyoshi M: Altered expression of beta-catenin without genetic mutation in intrahepatic cholangiocarcinoma. Mod Pathol 14: 900-905, 2001.

31. Serrano M, Hannon GJ and Beach D: A new regulatory motif in cell-cycle control causing specific inhibition of cyclin D/CDK4. Nature 366: 704-707, 1993.

32. Yang B, House MG, Guo M, Herman JG and Clark DP: Promoter methylation profiles of tumor suppressor genes in intrahepatic and extrahepatic cholangiocarcinoma. Mod Pathol 18: 412-420, 2005.

33. Ueki T, Hsing AW, Gao YT, Wang BS, Shen MC, Cheng J, Deng J, Fraumeni JF Jr and Rashid A: Alterations of p16 and prognosis in biliary tract cancers from a population-based study in China. Clin Cancer Res 10: 1717-1725, 2004.

34. Tozawa T, Tamura G, Honda T, Nawata S, Kimura W, Makino N, Kawata S, Sugai T, Suto T and Motoyama T: Promoter hypermethylation of DAP-kinase is associated with poor survival in primary biliary tract carcinoma patients. Cancer Sci 95: 736-740, 2004.

35. Tannapfel A, Sommerer F, Benicke M, Weinans L, Katalinic A, Geissler F, Uhlmann D, Hauss J and Wittekind C: Genetic and epigenetic alterations of the INK4a-ARF pathway in cholangiocarcinoma. J Pathol 197: 624-631, 2002.

36. Sasaki M, Yamaguchi J, Itatsu K, Ikeda H and Nakanuma Y: Over-expression of polycomb group protein EZH2 relates to decreased expression of p16 INK4a in cholangiocarcinogenesis in hepatolithiasis. J Pathol 215: 175-183, 2008.

37. Chinnasri P, Pairojkul C, Jearanaikoon P, Sripa B Bhudhisawasdi V, Tantimavanich $S$ and Limpaiboon T: Preferentially different mechanisms of inactivation of $9 \mathrm{p} 21$ gene cluster in liver fluke-related cholangiocarcinoma. Hum Pathol 40: 817-826, 2009.

38. Hong SM, Choi J, Ryu K, Ro JY and Yu E: Promoter hypermethylation of the p16 gene and loss of its protein expression is correlated with tumor progression in extrahepatic bile duct carcinomas. Arch Pathol Lab Med 130: 33-38, 2006.

39. Wong N, Li L, Tsang K, Lai PB, To KF and Johnson PJ: Frequent loss of chromosome $3 p$ and hypermethylation of RASSF1A in cholangiocarcinoma. J Hepatol 37: 633-639, 2002.

40. Abraham SC, Lee JH, Boitnott JK, Argani P, Furth EE and Wu TT: Microsatellite instability in intraductal papillary neoplasms of the biliary tract. Mod Pathol 15: 1309-1317, 2002. 
41. Limpaiboon T, Khaenam P, Chinnasri P, Soonklang M, Jearanaikoon P, Sripa B, Pairojkul C and Bhudhisawasdi V: Promoter hypermethylation is a major event of hMLH1 gene inactivation in liver fluke related cholangiocarcinoma. Cancer Lett 217: 213-219, 2005.

42. Foja S, Goldberg M, Schagdarsurengin U, Dammann R, Tannapfel A and Ballhausen WG: Promoter methylation and loss of coding exons of the fragile histidine triad (FHIT) gene in intrahepatic cholangiocarcinomas. Liver Int 25: 1202-1208, 2005.

43. Liu XF, Zhu SG, Zhang H, Xu Z, Su HL, Li SJ and Zhou XT: The methylation status of the TMS1/ASC gene in cholangiocarcinoma and its clinical significance. Hepatobiliary Pancreat Dis Int 5: 449-453, 2006.

44. Koga Y, Kitajima Y, Miyoshi A, Sato K, Kitahara K, Soejima H and Miyazaki K: Tumor progression through epigenetic gene silencing of $\mathrm{O}(6)$-methylguanine-DNA methyltransferase in human biliary tract cancers. Ann Surg Oncol 12: 354-363, 2005.

45. Tischoff I, Markwarth A, Witzigmann H, Uhlmann D, Hauss J, Mirmohammadsadegh A, Wittekind C, Hengge UR and Tannapfel A: Allele loss and epigenetic inactivation of 3p21.3 in malignant liver tumors. Int J Cancer 115: 684-689, 2005.

46. Sriraksa R, Zeller C, El-Bahrawy MA, Dai W, Daduang J, Jearanaikoon P, Chau-In S, Brown R and Limpaiboon T: $\mathrm{CpG}$-island methylation study of liver fluke-related cholangiocarcinoma. Br J Cancer 104: 1313-1318, 2011.

47. Khaenam P, Jearanaikoon P, Pairojkul C, Bhudhisawasdi V and Limpaiboon T: Genetic and epigenetic alterations of RIZ1 and the correlation to clinicopathological parameters in liver fluke-related cholangiocarcinoma. Exp Ther Med 1: 385-390, 2010.

48. Khaenam P, Niibori A, Okada S, Jearanaikoon P, Araki N and Limpaiboon T: Contribution of RIZ1 to regulation of proliferation and migration of a liver fluke-related cholangiocarcinoma cell. Asian Pac J Cancer Prev 13: 4007-4011, 2012.

49. Nakanuma Y,Uchida T, Sato Y and Uesaka K: An S100P-positive biliary epithelial field is a preinvasive intraepithelial neoplasm in nodular-sclerosing cholangiocarcinoma. Hum Pathol 60: 46-57, 2017.

50. Khorasanizadeh S: The nucleosome: From genomic organization to genomic regulation. Cell 116: 259-272, 2004.

51. Berger SL: Histone modifications in transcriptional regulation. Curr Opin Genet Dev 12: 142-148, 2002.

52. Grant PA: A tale of histone modifications. Genome Biol 2: Reviews0003, 2001.

53. Taby R and Issa JP: Cancer epigenetics. CA Cancer J Clin 60 376-392, 2010

54. Shukla V, Vaissiere T and Herceg Z: Histone acetylation and chromatin signature in stem cell identity and cancer. Mutat Res 637: 1-15, 2008

55. Esteller M: Epigenetics in cancer. N Engl J Med 358: 1148-1159, 2008 .

56. Cheung P and Lau P: Epigenetic regulation by histone methylation and histone variants. Mol Endocrinol 19: 563-573, 2005

57. Morine Y, Shimada M, Iwahashi S, Utsunomiya T, Imura S, Ikemoto T, Mori H, Hanaoka J and Miyake H: Role of histone deacetylase expression in intrahepatic cholangiocarcinoma. Surgery 151: 412-419, 2012

58. Baradari V, Höpfner M, Huether A, Schuppan D and Scherübl H: Histone deacetylase inhibitor MS-275 alone or combined with bortezomib or sorafenib exhibits strong antiproliferative action in human cholangiocarcinoma cells. World J Gastroenterol 13 4458-4466, 2007.

59. Xu LN, Wang X and Zou SQ: Effect of histone deacetylase inhibitor on proliferation of biliary tract cancer cell lines. World J Gastroenterol 14: 2578-2581, 2008.

60. Bluethner T, Niederhagen M, Caca K, Serr F, Witzigmann H, Moebius C, Mossner J and Wiedmann M: Inhibition of histone deacetylase for the treatment of biliary tract cancer: A new effective pharmacological approach. World J Gastroenterol 13: 4761-4770, 2007

61. Bartel DP: MicroRNAs: Genomics, biogenesis, mechanism, and function. Cell 116: 281-297, 2004.

62. Brennecke J, Stark A, Russell RB and Cohen SM: Principles of microRNA-target recognition. PLoS Biol 3: e85, 2005.

63. Chuang JC and Jones PA: Epigenetics and microRNAs. Pediatr Res 61: 24R-29R, 2007.

64. Ehrlich L, Hall C, Venter J, Dostal D, Bernuzzi F, Invernizzi P, Meng F, Trzeciakowski JP, Zhou T, Standeford H, et al: miR-24 inhibition increases menin expression and decreases cholangiocarcinoma proliferation. Am J Pathol 187: 570-580, 2017.
65. Stutes M, Tran S and DeMorrow S: Genetic and epigenetic changes associated with cholangiocarcinoma: From DNA methylation to microRNAs. World J Gastroenterol 13: 6465-6469, 2007.

66. Zhang J, Han C and Wu T: MicroRNA-26a promotes cholangiocarcinoma growth by activating $\beta$-catenin. Gastroenterology 143 246-256 e8, 2012.

67. Goeppert B, Ernst C, Baer C, Roessler S, Renner M, Mehrabi A, Hafezi M, Pathil A, Warth A, Stenzinger A, et al: Cadherin-6 is a putative tumor suppressor and target of epigenetically dysregulated miR-429 in cholangiocarcinoma. Epigenetics 11: 780-790, 2016.

68. Karakatsanis A,Papaconstantinou I, Gazouli M,Lyberopoulou A, Polymeneas G and Voros D: Expression of microRNAs, miR-21, miR-31, miR-122, miR-145, miR-146a, miR-200c, miR-221, miR-222, and miR-223 in patients with hepatocellular carcinoma or intrahepatic cholangiocarcinoma and its prognostic significance. Mol Carcinog 52: 297-303, 2013

69. Braconi C, Huang N and Patel T: MicroRNA-dependent regulation of DNA methyltransferase-1 and tumor suppressor gene expression by interleukin-6 in human malignant cholangiocytes. Hepatology 51: 881-890, 2010.

70. Zeng B, Li Z, Chen R, Guo N, Zhou J, Zhou Q, Lin Q, Cheng D, Liao Q, Zheng L and Gong Y: Epigenetic regulation of miR-124 by hepatitis $C$ virus core protein promotes migration and invasion of intrahepatic cholangiocarcinoma cells by targeting SMYD3. FEBS Lett 586: 3271-3278, 2012.

71. Li B, Han Q, Zhu Y, Yu Y, Wang J and Jiang X: Down-regulation of miR-214 contributes to intrahepatic cholangiocarcinoma metastasis by targeting Twist. FEBS J 279: 2393-2398, 2012.

72. Scott GK, Mattie MD, Berger CE, Benz SC and Benz CC: Rapid alteration of microRNA levels by histone deacetylase inhibition. Cancer Res 66: 1277-1281, 2006.

73. Valeri N, Vannini I, Fanini F, Calore F, Adair B and Fabbri M: Epigenetics, miRNAs, and human cancer: A new chapter in human gene regulation. Mamm Genome 20: 573-580, 2009.

74. Han L, Witmer PD, Casey E, Valle D and Sukumar S: DNA methylation regulates MicroRNA expression. Cancer Biol Ther 6: 1284-1288, 2007.

75. Schmitt AM and Chang HY: Long noncoding RNAs in cancer pathways. Cancer Cell 29: 452-463, 2016.

76. Wang WT, Ye H, Wei PP, Han BW, He B, Chen ZH and Chen YQ: LncRNAs H19 and HULC, activated by oxidative stress, promote cell migration and invasion in cholangiocarcinoma through a ceRNA manner. J Hematol Oncol 9: 117, 2016.

77. Yang W, Li Y, Song X, Xu J and Xie J: Genome-wide analysis of long noncoding RNA and mRNA co-expression profile in intrahepatic cholangiocarcinoma tissue by RNA sequencing. Oncotarget 8: 26591-26599, 2017

78. Wang J, Xie H, Ling Q, Lu D, Lv Z, Zhuang R, Liu Z, Wei X, Zhou L, Xu X and Zheng S: Coding-noncoding gene expression in intrahepatic cholangiocarcinoma. Transl Res 168: 107-121, 2016.

79. Jiang XM, Li ZL, Li JL, Zheng WY, Li XH, Cui YF and Sun DJ: LncRNA CCAT1 as the unfavorable prognostic biomarker for cholangiocarcinoma. Eur Rev Med Pharmacol Sci 21: 1242-1247, 2017.

80. Shi X, Zhang H, Wang M, Xu X, Zhao Y,He R, Zhang M,Zhou M, Li X, Peng F, et al: LncRNA AFAP1-AS1 promotes growth and metastasis of cholangiocarcinoma cells. Oncotarget 8: 58394-58404, 2017.

81. Wan M, Zhang FM, Li ZL, Kang PC, Jiang PM, Wang YM, Wang ZD, Zhong XY, Li CL, Wang $\mathrm{H}$, et al: Identifying survival-associated ceRNA clusters in cholangiocarcinoma. Oncol Rep 36: 1542-1550, 2016.

82. Tan X, Huang Z and Li X: Long non-coding RNA MALAT1 interacted with miR-204 to modulates human hilar cholangiocarcinoma proliferation, migration and invasion by targeting CXCR4. J Cell Biochem 118: 3643-3653, 2017.

83. Ma SL, Li AJ, Hu ZY, Shang FS and Wu MC: Coexpression of the carbamoylphosphate synthase 1 gene and its long noncoding RNA correlates with poor prognosis of patients with intrahepatic cholangiocarcinoma. Mol Med Rep 12: 7915-7926, 2015.

84. Parasramka M, Yan IK, Wang X, Nguyen P, Matsuda A, Maji S, Foye C, Asmann Y and Patel T: BAP1 dependent expression of long non-coding RNA NEAT-1 contributes to sensitivity to gemcitabine in cholangiocarcinoma. Mol Cancer 16: 22, 2017. 
85. Davaadorj M, Saito Y, Morine Y, Ikemoto T, Imura S, Takasu C, Yamada S, Hiroki T, Yoshikawa M and Shimada M: Loss of secreted frizzled-related protein-1 expression is associated with poor prognosis in intrahepatic cholangiocarcinoma. Eur J Surg Oncol 43: 344-350, 2017

86. Davaadorj M, Imura S, Saito YU, Morine Y, Ikemoto T, Yamada S, Takasu C, Hiroki T, Yoshikawa M and Shimada M: Loss of SFRP1 expression is associated with poor prognosis in hepatocellular carcinoma. Anticancer Res 36: 659-664, 2016.

87. Khoontawad J, Pairojkul C, Rucksaken R, Pinlaor P, Wongkham C, Yongvanit P, Pugkhem A, Jones A, Plieskatt J, Potriquet J, et al: Differential protein expression marks the transition from infection with Opisthorchis viverrini to cholangiocarcinoma. Mol Cell Proteomics 16: 911-923, 2017.

88. Sempoux C, Jibara G, Ward SC, Fan C, Qin L, Roayaie S, Fiel MI, Schwartz M and Thung SN: Intrahepatic cholangiocarcinoma: New insights in pathology. Semin Liver Dis 31: 49-60, 2011.

89. Lok T, Chen L, Lin F and Wang HL: Immunohistochemical distinction between intrahepatic cholangiocarcinoma and pancreatic ductal adenocarcinoma. Hum Pathol 45: 394-400, 2014.

90. Kanzawa M, Sanuki T, Onodera M, Fujikura K, Itoh T and Zen Y: Double immunostaining for maspin and p53 on cell blocks increases the diagnostic value of biliary brushing cytology. Pathol Int 67: 91-98, 2017.

91. Zen Y, Britton D, Mitra V, Pike I, Sarker D, Itoh T, Heaton N and Quaglia A: Tubulin $\beta$-III: A novel immunohistochemical marker for intrahepatic peripheral cholangiocarcinoma. Histopathology 65: 784-792, 2014.

92.Mustafa MZ, Nguyen VH, Le Naour F, De Martin E, Beleoken E, Guettier C, Johanet C, Samuel D, Duclos-Vallee JC and Ballot E: Autoantibody signatures defined by serological proteome analysis in sera from patients with cholangiocarcinoma. J Transl Med 14: 17, 2016

93. Rucksaken R, Pairojkul C, Pinlaor P, Khuntikeo N, Roytrakul S, Selmi C and Pinlaor S: Plasma autoantibodies against heat shock protein 70, enolase 1 and ribonuclease/angiogenin inhibitor 1 as potential biomarkers for cholangiocarcinoma. PLoS One 9: e103259, 2014

94.Le Faouder J, Laouirem S, Alexandrov T, Ben-Harzallah S, Léger T, Albuquerque M, Bedossa P and Paradis V: Tumoral heterogeneity of hepatic cholangiocarcinomas revealed by MALDI imaging mass spectrometry. Proteomics 14: 965-972, 2014.

95. Maeda S, Morikawa T, Takadate T, Suzuki T, Minowa T, Hanagata N, Onogawa T, Motoi F, Nishimura T and Unno M Mass spectrometry-based proteomic analysis of formalin-fixed paraffin-embedded extrahepatic cholangiocarcinoma. J Hepatobiliary Pancreat Sci 22: 683-691, 2015.

96. Stephenson B, Shimwell N, Humphreys E, Ward D, Adams D, Martin A and Afford S: Quantitative assessment of the cell surface proteome to identify novel therapeutic targets in cholangiocarcinoma. Lancet 1 (Suppl 385): S94, 2015.

97. Janvilisri T, Leelawat K, Roytrakul S, Paemanee A and Tohtong R: Novel serum biomarkers to differentiate cholangiocarcinoma from benign biliary tract diseases using a proteomic approach. Dis Markers 2015: 105358, 2015.

98. Adisakwattana P, Suwandittakul N, Petmitr S, Wongkham S, Sangvanich P and Reamtong O: ALCAM is a novel cytoplasmic membrane protein in TNF- $\alpha$ stimulated invasive cholangiocarcinoma cells. Asian Pac J Cancer Prev 16: 3849-3856, 2015.

99. Wasuworawong K, Roytrakul S, Paemanee A, Jindapornprasert K and Komyod W: Comparative proteomic analysis of human cholangiocarcinoma cell lines: S100A2 as a potential candidate protein inducer of invasion. Dis Markers 2015: 629367, 2015.

100. Haonon O, Rucksaken R, Pinlaor P, Pairojkul C, Chamgramol Y, Intuyod $\mathrm{K}$, Onsurathum $\mathrm{S}$, Khuntikeo $\mathrm{N}$ and Pinlaor $\mathrm{S}$ : Upregulation of 14-3-3 eta in chronic liver fluke infection is a potential diagnostic marker of cholangiocarcinoma. Proteomics Clin Appl 10: 248-256, 2016.

101. Seol MA, Chu IS, Lee MJ, Yu GR, Cui XD, Cho BH, Ahn EK, Leem SH, Kim IH and Kim DG: Genome-wide expression patterns associated with oncogenesis and sarcomatous transdifferentation of cholangiocarcinoma. BMC Cancer 11: 78, 2011.
102. Yang XW, Li L, Hou GJ, Yan XZ, Xu QG, Chen L, Zhang BH and Shen F: STAT3 overexpression promotes metastasis in intrahepatic cholangiocarcinoma and correlates negatively with surgical outcome. Oncotarget 8: 7710-7721, 2017.

103. Braconi C, Swenson E, Kogure T, Huang N and Patel T: Targeting the IL- 6 dependent phenotype can identify novel therapies for cholangiocarcinoma. PLoS One 5: e15195, 2010.

104. Yoo CB and Jones PA: Epigenetic therapy of cancer: Past, present and future. Nat Rev Drug Discov 5: 37-50, 2006.

105. Beisler JA: Isolation, characterization, and properties of a labile hydrolysis product of the antitumor nucleoside, 5-azacytidine. J Med Chem 21: 204-208, 1978.

106. Cheng JC, Weisenberger DJ, Gonzales FA, Liang G, Xu GL, $\mathrm{Hu}$ YG, Marquez VE and Jones PA: Continuous zebularine treatment effectively sustains demethylation in human bladder cancer cells. Mol Cell Biol 24: 1270-1278, 2004

107. Marquez VE, Barchi JJ Jr, Kelley JA, Rao KV, Agbaria R, Ben-Kasus T, Cheng JC, Yoo CB and Jones PA: Zebularine: A unique molecule for an epigenetically based strategy in cancer chemotherapy. The magic of its chemistry and biology. Nucleosides Nucleotides Nucleic Acids 24: 305-318, 2005

108. Nakamura K, Nakabayashi K, Htet Aung K, Aizawa K, Hori N, Yamauchi J, Hata K and Tanoue A: DNA methyltransferase inhibitor zebularine induces human cholangiocarcinoma cell death through alteration of DNA methylation status. PLoS One 10: e0120545, 2015.

109. Kelly WK and Marks PA: Drug insight: Histone deacetylase inhibitors-development of the new targeted anticancer agent suberoylanilide hydroxamic acid. Nat Clin Pract Oncol 2: $150-157,2005$.

110. Sharma S, Kelly TK and Jones PA: Epigenetics in cancer. Carcinogenesis 31: 27-36, 2010.

111. Sriraksa R and Limpaiboon T: Histone deacetylases and their inhibitors as potential therapeutic drugs for cholangiocarcinoma-cell line findings. Asian Pac J Cancer Prev 14: 2503-2508, 2013.

112. Nakagawa S, Sakamoto Y, Okabe H, Hayashi H, Hashimoto D, Yokoyama N, Tokunaga R, Sakamoto K, Kuroki H, Mima K, et al: Epigenetic therapy with the histone methyltransferase EZH2 inhibitor 3-deazaneplanocin A inhibits the growth of cholangiocarcinoma cells. Oncol Rep 31: 983-988, 2014.

113. Gores GJ: Early detection and treatment of cholangiocarcinoma. Liver Transpl 6 (6 Suppl 2): S30-S34, 2000.

114. Nakaoka T, Saito Y and Saito H: Aberrant DNA methylation as a biomarker and a therapeutic target of cholangiocarcinoma. Int J Mol Sci 18: E1111, 2017.

115. Jusakul A, Cutcutache I, Yong $\mathrm{CH}$, Lim JQ, Huang MN, Padmanabhan N, Nellore V, Kongpetch S, Ng AWT, $\mathrm{Ng} \mathrm{LM}$, et al: Whole-genome and epigenomic landscapes of etiologically distinct subtypes of cholangiocarcinoma. Cancer Discov 7: 1116-1135, 2017

116. Ettel M, Eze O and Xu R: Clinical and biological significance of precursor lesions of intrahepatic cholangiocarcinoma. World J Hepatol 7: 2563-2570, 2015.

117. Fujimoto A, Furuta M, Shiraishi Y, Gotoh K, Kawakami Y, Arihiro K, Nakamura T, Ueno M, Ariizumi S, Nguyen HH, et al: Whole-genome mutational landscape of liver cancers displaying biliary phenotype reveals hepatitis impact and molecular diversity. Nat Commun 6: 6120, 2015

118. Komuta M, Govaere O, Vandecaveye V, Akiba J, Van Steenbergen W, Verslype C, Laleman W, Pirenne J, Aerts R, Yano H, et al: Histological diversity in cholangiocellular carcinoma reflects the different cholangiocyte phenotypes. Hepatology 55: 1876-1888, 2012.

119. Rizvi S and Gores GJ: Pathogenesis, diagnosis, and management of cholangiocarcinoma Gastroenterology 145: 1215-1229, 2013.

This work is licensed under a Creative Commons Attribution-NonCommercial-NoDerivatives 4.0 International (CC BY-NC-ND 4.0) License. 